\title{
Over-expression of Slc30a8/ZnT8 selectively in the mouse a cell impairs glucagon release and responses to hypoglycemia
}

Antonia Solomou', Erwann Philippe ${ }^{2}$, Pauline Chabosseau', Stephanie Migrenne-Li², Julien Gaitan², Jochen Lang ${ }^{3}$, Christophe Magnan ${ }^{2}$ and Guy A. Rutter ${ }^{1 *}$ (D)

\begin{abstract}
Background: The human SLC3OA8 gene encodes the secretory granule-localised zinc transporter ZnT8 whose expression is chiefly restricted to the endocrine pancreas. Single nucleotide polymorphisms (SNPS) in the human SLC30A8 gene have been associated, through genome-wide studies, with altered type 2 diabetes risk. In addition to a role in the control of insulin release, recent studies involving targeted gene ablation from the pancreatic a cell (Solomou et al., J Biol Chem 290(35):21432-42) have also implicated ZnT8 in the control of glucagon release. Up to now, however, the possibility that increased levels of the transporter in these cells may impact glucagon secretion has not been explored.
\end{abstract}

Methods: Here, we use a recently-developed reverse tetracyline transactivator promoter-regulated ZnT8 transgene to drive the over-expression of human ZnT8 selectively in the a cell in adult mice. Glucose homeostasis and glucagon secretion were subsequently assessed both in vivo during hypoglycemic clamps and from isolated islets in vitro.

Results: Doxyclin-dependent human ZnT8 mRNA expression was apparent in both isolated islets and in fluorescence-activated cell sorting- (FACS) purified a cells. Examined at 12 weeks of age, intraperitoneal glucose $(1 \mathrm{~g} / \mathrm{kg}$ ) tolerance was unchanged in transgenic mice versus wild-type littermates $(n=8-10$ mice/genotype, $p>0.05)$ and sensitivity to intraperitoneal insulin $(0.75 \mathrm{U} / \mathrm{kg})$ was similarly unaltered in transgenic animals. In contrast, under hyperinsulinemic-hypoglycemic clamp, a $\sim 45 \%(p<0.001)$ reduction in glucose infusion rate was apparent, and glucagon release was significantly $(\sim 40 \%, p<0.01)$ impaired, in transgenic mice. Correspondingly, examined in vitro, glucagon secretion was significantly reduced $(\sim 30 \%, p<0.05)$ from transgenic versus control islets at low, stimulatory glucose concentrations $(1 \mathrm{mM}, p<0.05)$ but not at high glucose $(17 \mathrm{mM})$ glucose $(p>0.05)$. Over-expression of ZnT8 in glucagonoma-derived aTC1-9 cells increased granule free $\mathrm{Zn}^{2+}$ concentrations consistent with a role for $\mathrm{Zn}^{2+}$ in this compartment in the action of $\mathrm{ZnT} 8$ on glucagon secretion.

Conclusions: Increased ZnT8 expression, and a likely increase in intragranular free $\mathrm{Zn}^{2+}$ concentration, is deleterious in pancreatic a cells for stimulated glucagon release. These data provide further evidence that type 2 diabetes-associated polymorphisms in the SLC30A8/ZnT8 gene may act in part via alterations in glucagon release and suggest that ZnT8 activation may restrict glucagon release in some settings.

\footnotetext{
* Correspondence: g.rutter@imperial.ac.uk

${ }^{1}$ Section of Cell Biology and Functional Genomics, Division of Diabetes

Endocrinology and Metabolism, Department of Medicine, Imperial College

London, Imperial Centre for Translational and Experimental Medicine,

Hammersmith Hospital, du Cane Road, London W12 0NN, UK

Full list of author information is available at the end of the article
} 


\section{Background}

Type 2 diabetes mellitus (T2D) is a complex polygenic disease which affects $\sim 1$ in 12 of the adult population and consumes $\sim 10 \%$ of the health care budgets of most westernized societies [1]. Although genome-wide association (GWA) and other studies have in recent years identified multiple loci as affecting the risk T2D [2, 3], functional work in model systems remains important if we are fully to understand the physiological role(s), and potential as pharmacotherapeutic targets, of the implicated genes. Most such studies up to now have used gene deletion in mice, inactivating candidates either globally or in disease-relevant tissues $[4,5]$. In the case of the endocrine pancreas-restricted secretory granule zinc transporter SLC30A8/ZnT8, identified in GWA studies for T2D [6], this approach has been pivotal in highlighting the role of the transporter in the control of secretory granule formation and $\mathrm{Zn}^{2+}$ storage $[7,8]$ insulin secretion [9] and hepatic clearance of the hormone [10].

Nevertheless, the impact of SLC30A8 risk variants [2] on ZnT8 activity and T2D risk are still debated. The common risk variant rs13266634 in the SLC30A8 gene encodes an amino acid exchange (R325W) which is believed to lower transporter activity $[7,11]$. On the other hand, rare truncating variants of $\mathrm{ZnT} 8$ are protective [12]. The reasons for this complex relationship between ZnT8 levels and disease risk are not fully understood $[13,14]$. Whilst the role of the transporter in the control of insulin secretion has been the chief focus of interest in recent years, the observation that $\mathrm{ZnT} 8$ is also expressed in the $\alpha$ cell in both rodents [7] and humans [15] leads to the possibility that an action via glucagon release may also affect diabetes risk. Indeed, $\mathrm{Zn}^{2+}$ ions have been shown by autometallography [16] to be present in the secretory granule of $\alpha$ as well as $\beta$ cells. Correspondingly, we have recently shown, by $\alpha$ cellselective deletion of ZnT8 in mice [17], an important role for this transporter in the control of glucagon secretion.

Importantly, and as well as providing insights into the aetiopathology of $\mathrm{T} 2 \mathrm{D}$, changes in the normal release of glucagon may also have consequences for glycemic control in Type 1 diabetes (T1D). In the latter disease, inadequate responses to hypoglycaemia constitute a substantial risk and limit the use of insulin treatment to achieve good glycemic control and minimize disease complications [18].

Although investigating the impact of the absence of a gene is usually highly informative, its overexpression may also provide important insights, particularly with respect to the possible impact of pharmacological approaches which activate the gene or its product. Inducible expression systems are consequently often used in mice to achieve both temporal and spatial (i.e. tissue- specific) control of the expression of a given gene. Components of the Tet Switches [19] originate from the tetracycline (Tet) resistance operon in E.coli and belong to one of the most evolved gene regulation systems. "Tet-Off" and "Tet-On" systems are used in the majority of the studies involving inducible expression. The TetOff system was initially developed in 1992 and in the presence of the antibiotic tetracycline the expression from a Tet-inducible promoter is decreased [19].

In order to utilize tetracycline as a regulator of transcription, a tetracycline-controlled transactivator (tTA) is controlled by fusion of the tetracycline repressor with a transcriptional activation domain from Herpes Simplex Virus (HSV). Thus, in the absence of tetracycline, the fusion protein can bind tet operator sequences and promote transcription while in the presence of the antibiotic, its binding to the protein makes it unable to bind DNA leading to a decrease in gene expression. The "Tet-On" system was later developed by mutation of the repressor portion of the tTA to create a reverse tetracycline controlled transactivator (rtTA) that relies on tetracycline for induction of gene expression rather than repression [20]. The system was first used in the pancreatic $\beta$-cell by Efrat and colleagues [21] and about ten years later in the $\alpha$-cell [22].

Recently, our laboratory used this approach to determine the effects of ZnT8 over-expression in the pancreatic $\beta$-cell in mice, driving rtTA expression with the rat insulin 2 promoter [23]. In the present study, the rtTA sequence was placed under the control of the preproglucagon promoter in Glu-rtTA mice [22] allowing us to drive the expression of ZnT8 selectively in the $\alpha$-cell in the adult mouse.

Using this approach we have investigated the effect of ZnT8 overexpression on glucagon secretion. Glu-rtTA mice were therefore crossed to mice bearing a human ZnT8 transgene whose expression was driven by the tet operator sequence. In contrast to the recently described effect of $\alpha$ cell-selective deletion of ZnT8 to enhance glucagon secretion at low glucose [17], we demonstrate that ZnT8 over-expression results in the suppression of glucagon release during hypoglycaemia, consequently enhancing glucose clearance.

\section{Methods \\ Materials}

Chemicals and biochemical were purchased from SigmaAldrich (Poole, Dorset, U.K.) unless otherwise indicated.

\section{Generation and genotyping of aZnT8Tg mice}

Glu-rtTA mice, which possess a $1.1 \mathrm{~kb}$ region of the preproglucagon promoter upstream of rtTA [22], were crossed to animals bearing a human $\mathrm{ZnT}$ 8-overexpressing transgene (ZnT8Tg) as described in [23]. Heterozygous Glu- 
rtTA mice were crossed to homozygous ZnT8Tg animals. Two ZnT8Tg founders were used, corresponding to lines \#31 and \#23 in [23]. The litters comprised Glu-rtTA offspring, which expressed the human ZnT8 transgene after induction with docycycline (as described below), while littermates bearing the $\mathrm{ZnT} 8 \mathrm{Tg}$ allele alone, and born at Mendelian frequency (50 \%), were used as controls. Doxycyclin, a tetracycline derivative, was given to all experimental mice in the drinking water $(2 \mathrm{~g} / \mathrm{L})$ from the age of six weeks in order to induce ZnT8 expression in Glu-rtTA ${ }^{+}: \mathrm{ZnT} \mathrm{Tg}^{+}$animals [22]. Animals were kept in a pathogenfree facility under a $12 \mathrm{~h}$ light-dark cycle with access to water and a standard mouse diet (Lillico Biotechnology). After weaning at 3-4 weeks of age mice were housed two to five per cage. All strains were maintained on a C57/ BL6/J background.

Genotyping for Glu-rtTA was performed using standard PCR on DNA extracted from ear biopsies (Fig. 1a) using the primers indicated in Table 1. For the ZnT8 transgene, qPCR was used to detect the presence in the genome of the firefly luciferase gene, included in the transgene in the antisense direction with respect to ZnT8 cDNA [23].

\section{Islet isolation and culture}

Mice were sacrificed by cervical dislocation and islets isolated essentially as described [24]. In brief, pancreata were inflated with collagenase solution at $1 \mathrm{ug} / \mathrm{ml}$ (Serva) and placed in a water bath at $37{ }^{\circ} \mathrm{C}$ for $10 \mathrm{~min}$. After centrifugation and washing islets were purified on a Histopaque 119 (Sigma) gradient, by centrifugation at $2500 \mathrm{rpm}$ for $20 \mathrm{~min}$. The islet layer was recovered and islets cultured in complete RPMI 1640 medium (Gibco; $11 \mathrm{mM}$ glucose) for $2-4 \mathrm{~h}$ at $37{ }^{\circ} \mathrm{C}$ islets before handpicking into fresh media.

\section{Islet dissociation, fluorescence-activated cell sorting (FACS) and FACS analysis}

FACS analysis was performed essentially as described [17]. After overnight incubation, 250-300 islets of the same genotype were handpicked and dissociated into single cells by repeated pipetting in $150 \mu$ l of Hank's based cell dissociation buffer (Invitrogen) containing $0.1 \%$ BSA and $0.1 \%$ trypsin. The reaction was stopped with the addition of FBS $(20 \mu$ l; Seralab). Cells were incubated in near-IR dead cell stain (Life technologies) for $20 \mathrm{~min}$. at $4{ }^{\circ} \mathrm{C}$, washed with PBA (PBS, $1 \%$ BSA, $0.1 \%$ azide) and fixed in $2 \%(\mathrm{w} / \mathrm{v})$ PFA for $10 \mathrm{~min}$. and then washed twice with PBA and once with Saponin (0.025\% in PBA) before 10 min incubation with Saponin at room temperature. Cells were incubated with primary antibodies against insulin or glucagon (see Table 2) before incubation with secondary antibodies (anti-mouse AF 405, anti- guinea pig AF 488, anti-rabbit AF 640) for $20 \mathrm{~min}$ and resuspension in PBA. The samples were run on a BD Fortessa Flow Cytometer (BD Bioscience).

\section{RNA extraction and CDNA synthesis}

Islets were washed once in phosphate-buffered saline (PBS) followed by addition of TRIzol (ThermoFisher). Chloroform (200 $\mu \mathrm{l}$ per $\mathrm{ml}$ of TRIzol) was added and after centrifugation the upper aqueous phase was removed and RNA was precipitated by adding $400 \mu \mathrm{l}$ isopropanol per $\mathrm{ml}$ of TRIzol. After re-centrifugation and washing the dried pellet was finally resuspended in nuclease-free water. The same quantity of RNA was used from each sample to perform a reverse transcription polymerase chain reaction (RT-PCR) and cDNA synthesis using random primers. cDNA was generated from RNA (up to $1 \mu \mathrm{g}$ ) using a High Capacity Reverse Transcription kit (Applied Biosystems) according the manufacturer's instructions using the following thermocycler protocol: 10 min $25^{\circ} \mathrm{C}, 2 \mathrm{~h} 37{ }^{\circ} \mathrm{C}, 5 \mathrm{~min} .85^{\circ} \mathrm{C}$, hold $4{ }^{\circ} \mathrm{C}$.

\section{Quantitative PCR (qPCR)}

For gene expression measurements cDNA $(2 \mu \mathrm{l})$ from the RT-PCR reaction above were used as template for quantitative Real Time PCR (qPCR) using a Fast SYBR Green Master Mix (Invitrogen) according to the manufacturer's instructions. The reaction was initiated at $50{ }^{\circ} \mathrm{C}$ for $2 \mathrm{~min}$. followed by the activation and pre-denaturation step at $95{ }^{\circ} \mathrm{C}$ for $10 \mathrm{~min}$. The run was made up of 40 cycles of $15 \mathrm{~s}$ at $95{ }^{\circ} \mathrm{C}$ and 1 min. at $60{ }^{\circ} \mathrm{C}$.

\section{aTC1.9 cell transfection}

$\alpha \mathrm{TC1} .9$ cells were transfected with a human ZnT8 (W325 variant) expression vector or with the corresponding empty vector (EV), using Lipofectamine2000 (LifeTechnologies) as previously described $[25,26]$ and according to the manufacturer's instruction. For cytosolic $\mathrm{Zn}^{2+}$ measurement, cells were co-transfected with an eCALWY-4 [27] expression vector. Imaging experiments were performed the day after transfection.

\section{Cytosolic $\mathrm{Zn}^{2+}$ measurement with eCALWY-4}

Cells on coverslips were washed twice in Krebs-HEPESbicarbonate (KHB) buffer $(140 \mathrm{mM} \mathrm{NaCl}, 3.6 \mathrm{mM} \mathrm{KCl}$, $0.5 \mathrm{mM} \mathrm{NaH}_{2} \mathrm{PO}_{4}, 0.2 \mathrm{mM} \mathrm{MgSO}_{4}, 1.5 \mathrm{mM} \mathrm{CaCl} 2$, $10 \mathrm{mM}$ HEPES, $25 \mathrm{mM} \mathrm{NaHCO}_{3}$ ), which was warmed, bubbled with 95:5 $\mathrm{O}_{2} / \mathrm{CO}_{2}$, set to $\mathrm{pH}$ 7.4, and contained $11 \mathrm{mM}$ glucose. Imaging of $\left[\mathrm{Zn}^{2+}\right]$ using eCALWY sensors [27] was carried out as optimized before [25, 26]. Briefly, cells were maintained at $37^{\circ} \mathrm{C}$ throughout with a heating stage (MC60, LINKAM, Scientific Instruments), and $\mathrm{KHB}$ was perifused (1.5 to $2 \mathrm{~mL} / \mathrm{min}$ ) with additions 

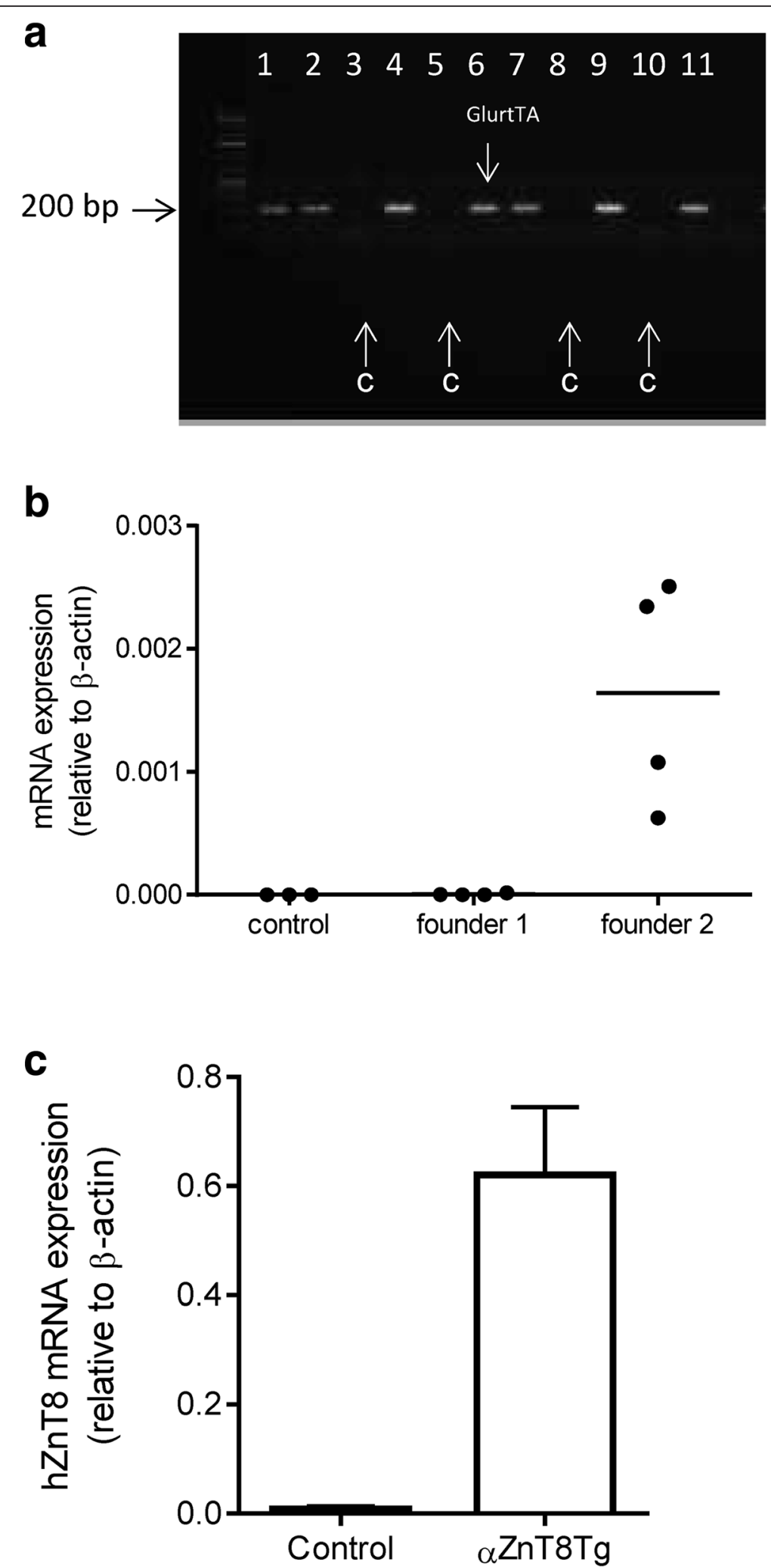

Fig. 1 (See legend on next page.) 
(See figure on previous page.)

Fig. 1 Overexpression of human ZnT8 in the a cell. a Genotyping by PCR. The Glu-rtTA transgene was amplified by standard PCR to identify control and transgenic animals. Lanes derived from control (lacking the GlrTTA transgene) mice are indicated with arrows as " $\mathrm{C}$ ". Samples from transgene-bearing mice are present in lanes 1,2,4,6,7,9,11. b Human ZnT8 expression in isolated islets. Total RNA was extracted from islets from control and transgenic mice. The levels of hZnT8 were assessed by RT-qPCR. c Human ZnT8 expression in purified a-cells. RNA was extracted from a-cells obtained from control or aZnT8Tg mice. The levels of hZnT8 mRNA were assessed by RT-qPCR

as stated in the figures. Images were captured at $433 \mathrm{~nm}$ monochromatic excitation wavelength (Polychrome IV, Till photonics) using an Olympus IX-70 wide-field microscope with a $40 \times / 1.35 \mathrm{NA}$ oil immersion objective and a zyla sCMOS camera (Andor Technology) controlled by Micromanager software. Acquisition rate was 20 images/min. Emitted light was splitted and filtered by a Dual-View beam splitter (Photometrics) equipped with a 505dcxn dichroic mirror and two emission filters (Chroma Technology, D470/24 for cerulean and D535/ 30 for citrine). Image analysis was performed with ImageJ software using a homemade macro and the fluorescence emission ratios were derived after subtracting background. Steady-state fluorescence intensity ratio citrine/cerulean ( $R$ ) was measured, then maximum and minimum ratios were determined to calculate free $\mathrm{Zn}^{2+}$ concentration using the following formula: $\left[\mathrm{Zn}^{2+}\right]=$ $K_{\mathrm{d}}\left(\mathrm{R}_{\max }-\mathrm{R}\right) /\left(\mathrm{R}-\mathrm{R}_{\min }\right)$. The maximum ratio $\left(\mathrm{R}_{\max }\right)$ was obtained upon intracellular zinc chelation with $50 \mu \mathrm{M}$ TPEN and the minimum ratio $\left(\mathrm{R}_{\mathrm{min}}\right)$ was obtain upon zinc saturation with $100 \mu \mathrm{M} \mathrm{ZnCl}_{2}$ in the presence of the $\mathrm{Zn}^{2+}$ ionophore, pyrithione $(5 \mu \mathrm{M})$.

\section{Granular $\mathrm{Zn}^{2+}$ Imaging with Zinpyr-4}

$\alpha$ TC1.9 cells were incubated for $20 \mathrm{~min}$. before imaging in $1 \mu \mathrm{M}$ Zinpyr-4 (Santa Cruz Biotechnology), and washed twice in imaging buffer. Acquisitions were performed as described above with additions as stated on the figures. Zinpyr-4 was excited at $488 \mathrm{~nm}$ wavelength and signal was collected through a 535/50 nm emission filter. Differences in Zinpyr4 mean intensity between EV and ZnT8-expressing cells were measured using ImageJ.

Table 1 PCR primers

\begin{tabular}{ll}
\hline Gene & Sequence \\
\hline$\beta$ Actin & FOR: CGAGTCGCGTCCACCC \\
Glucagon & REV: CATCCATGGCGAACTGGTG \\
& REV: CCATCAGCATGCCTCTCAAAT \\
Human ZnT8 & FOR: CTGTCATCGAAGCCTCCCTC \\
& REV: AAGGGCATGCACAAAAGCAG \\
Glu-rtTA & FOR: CATAAACGGCGCTCTGGAATACTCAATGGAGTCG \\
& REV: GCCGAGATGCACTTAGCCCCGTCGCGATGTGAGA \\
Luciferase & FOR: CAACTGCATAAGGCTATGAAGAGA \\
& REV: ATTTGATTCAGCCCATATCGTT \\
\hline
\end{tabular}

\section{Other methods}

Glucagon secretion was measured from islets essentially as described in detail in [17]. In brief, 18 sizematched islets per condition were incubated with constant agitation for $1 \mathrm{~h}$ in $0.5 \mathrm{~mL}$ Krebs-HEPES bicarbonate buffer at $37{ }^{\circ} \mathrm{C}$ with either $1 \mathrm{mM}$ or $17 \mathrm{mM}$ glucose, and total and secreted glucagon measured at the end of the incubations by radioimmunoassay (Millipore). Details of intraperitoneal glucose $(1 \mathrm{~g} / \mathrm{kg}$; IPGTT) and insulin (0.5 U/kg; IPITT) tolerance tests, and hypoglycemic clamps are provided in [17].

\section{Statistics}

Student's $t$ test was used to identify differences between two independent variables and assessments between multiple variables assessed by two-way ANOVA (with suitable correction from multiple tests), followed by Bonferroni's post hoc test. All analyses were performed using GraphPad Prism 6.0, and $p<0.05$ was considered significant. Values are presented as means \pm S.E.

\section{Results \\ Expression of human ZnT8 in transgenic islets}

Initially to check that the administration of doxycyclin was effective in inducing the overexpression of $\mathrm{ZnT}$, total RNA was extracted from isolated islets incubated overnight with doxycyclin $(5 \mu \mathrm{g} / \mathrm{ml})$. qPCR analysis revealed expression of the human form of $\mathrm{ZnT} 8$ in the mice containing both the overexpressing transgene and

Table 2 Antibodies

\begin{tabular}{llll}
\hline Primary & & & \\
Antibody & Species & Company & Dilution \\
ZnT8 & Rabbit & Mellitech & 1:200 \\
Glucagon & Mouse & Sigma & 1:1000 \\
Glucagon & Rabbit & Santa Cruz & 1:200 \\
Insulin & Guinea pig & Santa Cruz & 1:200 \\
Secondary & & & \\
Antibody & Species & Company & Dilution \\
Anti-mouse Alexa 568 & Goat & Invitrogen & 1:1000 \\
Anti-rabbit Alexa 488 & Goat & Invitrogen & 1:1000 \\
Anti-guinea pig Alexa 488 & Donkey & Invitrogen & 1:1000 \\
Anti-mouse Alexa 488 & Donkey & Invitrogen & 1:1000 \\
Anti-rabbit 568 & Goat & Invitrogen & 1:1000 \\
\hline
\end{tabular}


the Glu-rtTA but not in the control mice carrying only the ZnT8 transgene (Fig. 1b). We tested both founders that carried the transgene and observed that only founder 2 (\#31 from [23]) expressed detectable levels of human ZnT8. Consequently, offspring from this founder was used in all in experiments.

In order to obtain a more accurate assessment of the degree of overexpression in a pure $\alpha$-cell population and as opposed to islets, which are largely composed of $\beta$ cells [28], isolated islets were dissociated and stained with glucagon for fluorescence-activated cell sorting (FACS). RNA was then extracted from the sorted cells to check for expression of the human ZnT8 in the $\alpha$-cells obtained from transgenic and control animals (Fig. 1c). Whilst essentially absent from non-transgenic islets, hZnT8 mRNA was readily detected in islets from transgenic animals.

\section{Intraperitoneal glucose and insulin tolerance are unaltered in aZnT8Tg mice}

To assess whether glucose homeostasis in transgenic mice was altered, intraperitoneal glucose tolerance tests (IPGTTs) were performed on male (Fig. 2a) and female (Fig. 2b) mice aged 8 weeks. In neither case were any differences in the excursions in blood glucose observed between control and transgenic animals at any time point during the tests.

Insulin sensitivity was similarly determine by intraperitoneal insulin tolerance tests (ITTs) were performed on transgenic and control male (Fig. 2c) and female (Fig. 2d) mice at the age of 14 weeks. Again, no differences were observed between the responses of $\alpha \mathrm{ZnT} 8 \mathrm{Tg}$ and control mice.

\section{Trangenic mice require an elevated glucose infusion rate} (GIR) and display impaired glucagon secretion during hypoglycemic clamps

ITTs as described above could only be used safely (i.e. without life-threatening hypoglycaemia) to provide a limited decrease in blood glucose levels (to $\sim 4 \mathrm{mM}$ ), above the usual threshold for substantial glucagon release in the mouse [29]. In order to elicit a more marked, but stable, decrease in blood glucose levels, where glucagon release is likely to be more strongly stimulated, hypoglycaemic clamps [17] were performed. Male mice were thus rendered hypoglycaemic by continuous intravenous administration of insulin (Fig. 3a). Under these conditions ZnT8-overexpressing mice
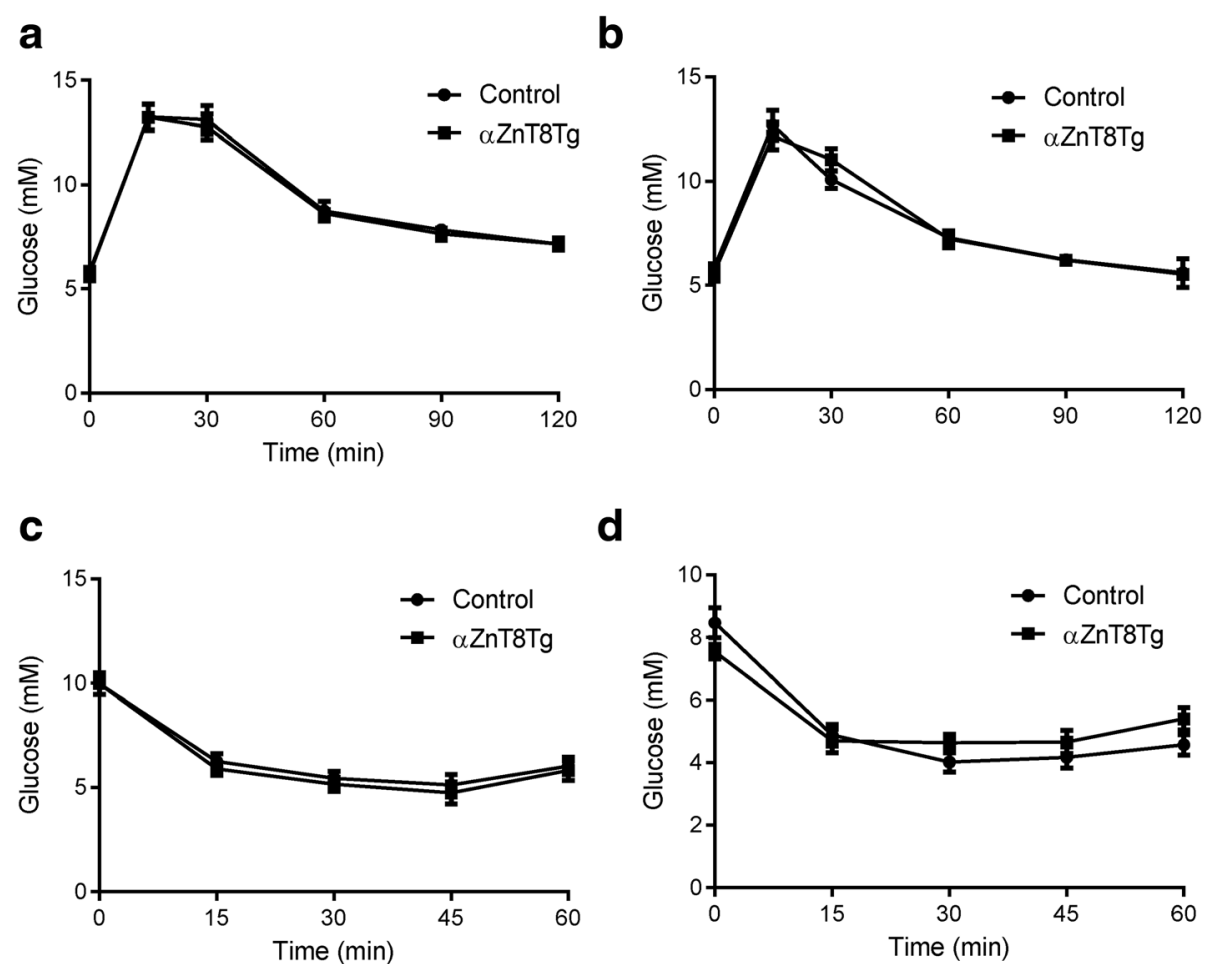

Fig. 2 Glucose and insulin tolerance in aZnT8Tg mice. Intraperitoneal glucose tolerance tests were performed on control and transgenic male (a) and female (b) mice at 8 weeks of age. $n=8-10$ mice/genotype. Animals were fasted for $16 \mathrm{~h}$ before injection of $1 \mathrm{~g} / \mathrm{kg}$ glucose. Blood glucose was sampled after venisection of the tail vein at the indicated times, and quantified using an automated glucometer (AccuCheck, Roche). c, $\mathbf{d}$ Insulin sensitivity. Intraperitoneal insulin tolerance tests performed on 12 week old male (c) and female (d) mice fasted for $5 \mathrm{~h}$ and injected with $0.5 \mathrm{U} / \mathrm{kg}$ insulin. $n=9-10$ mice per genotype. Blood sampling was performed as in $(\mathbf{a}, \mathbf{b})$ 


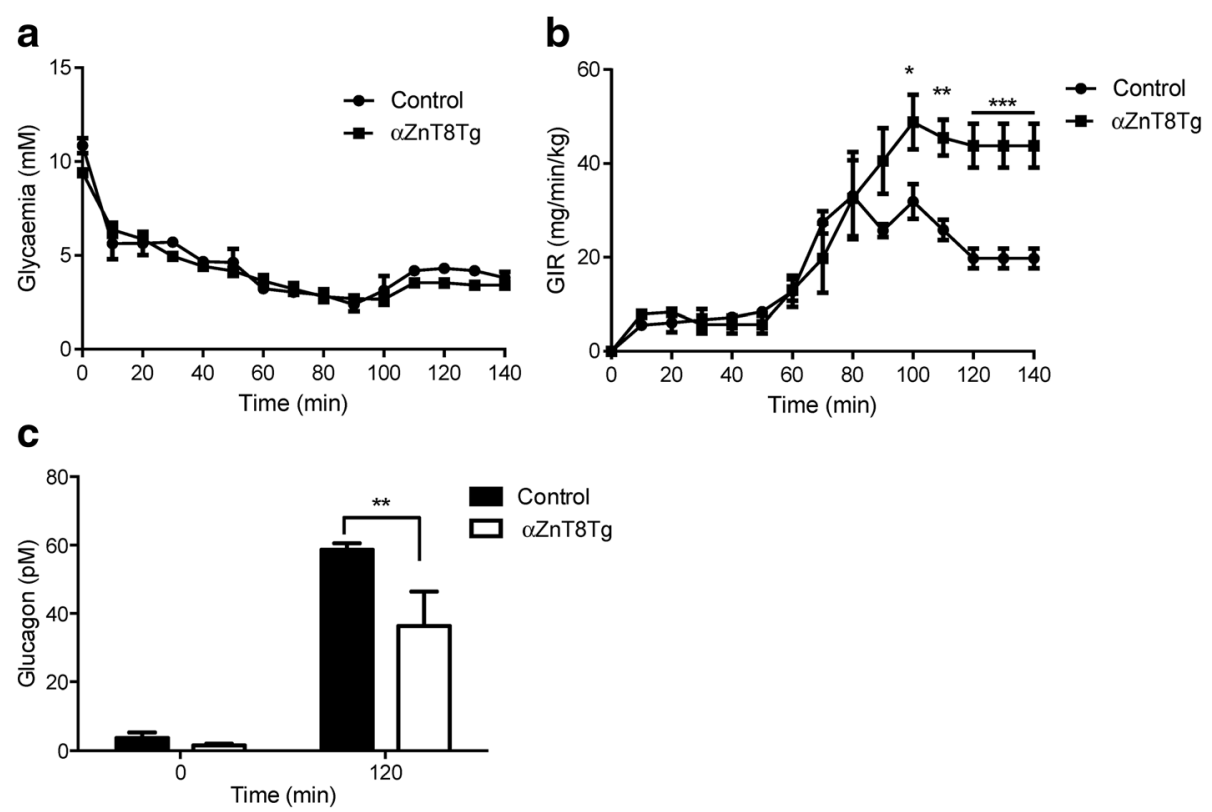

Fig. 3 Elevated glucose infusion rates in aZnT8 KO mice during hypoglycaemic hyperinsulinaemic clamps. Experiments were performed on 12 week old male mice. Animals were fasted for $4 \mathrm{~h}$ and rendered hypoglycaemic by infusion of insulin (a). Glucose levels were monitored and glucose infusion rate adjusted accordingly to keep the mice in a hypoglycaemic state at $\sim 60-70 \%$ of the initial value (b). c Blood was collected from tail vein at times 0 and $120 \mathrm{~min}$ in tubes filled with EGTA (1.6 mg/ml, Sigma) and aprotinin (250 k-international units/ml; Sigma) for glucagon measurement.. $n=4$ mice per genotype. Data are mean \pm SEM, ${ }^{*} P<0.05,{ }^{* *} P<0.01,{ }^{* *} P<0.005$. Other details are given in the Methods section

required a significantly higher glucose infusion rate (GIR) to maintain hypoglycaemia compared to control mice (Fig. 3b), suggesting an impairment in glucagon release. Plasma glucagon levels were consequently measured prior to the onset of hypoglycaemia and at 120 min. after the beginning of insulin infusion (Fig. 3c). Whilst no differences were observed between glucagon levels in control and transgenic mice at the earlier time point, concentrations of the hormone at $120 \mathrm{~min}$ were $45 \%$ lower $(p<0.01)$ in transgenic versus control mice (Fig. 3c).

\section{Glucagon secretion is impaired in islets isolated from aZnT8Tg mice}

We sought next to determine whether the impaired glucagon secretion observed in vivo in $\alpha \mathrm{ZnT} 8 \mathrm{Tg}$ mice chiefly reflected a cell autonomous effect in the $\alpha$-cell, or a more complex set of changes in the autocrine response to hypoglycaemia, potentially involving multiple tissues (brain, adrenals etc.) [30, 31]. Correspondingly, we observed that when isolated islets were incubated in $1 \mathrm{mM}$ glucose (a concentration in the range which strongly stimulates glucagon release from $\alpha$-cells) [29], those overexpressing ZnT8 secreted significantly less $(\sim 20 \%, p<0.05)$ glucagon that control islets (Fig. 4). At $17 \mathrm{mM}$ glucose the responses did not differ between islets expressing ZnT8 selectively in the $\alpha$-cell and control islets.
Impact of ZnT8 over-expression on granular and cytosolic free $\mathrm{Zn}^{2+}$ concentrations in clonal a-cells

In order to determine whether $\mathrm{ZnT} 8$ overexpression may act via changes in subcellular free $\mathrm{Zn}^{2+}$ concentrations, we monited the latter in secretory granules (Fig. 5)

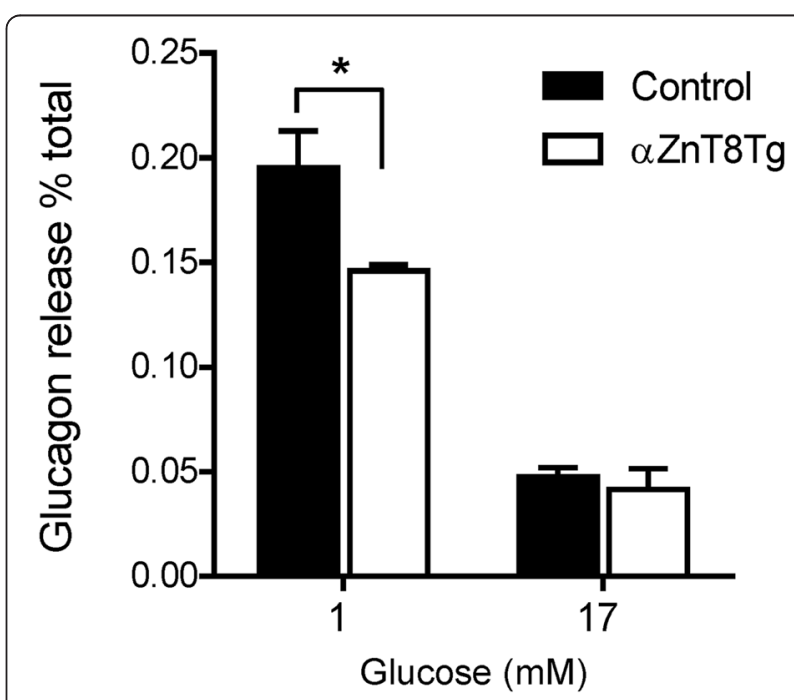

Fig. 4 Glucagon secretion from aZnT8Tg islets is impaired in vitro. Isolated islets were incubated at $1 \mathrm{mM}$ or $17 \mathrm{mM}$ glucose for $1 \mathrm{~h}$. Released glucagon was measured using an HTRF assay. Transgenic islets secreted significantly less glucagon compared to control when incubated at $1 \mathrm{mM}$ glucose. Data are mean $\pm \mathrm{SEM}, n=4$ separate experiments involving islets from 3 to 4 mice per genotype, ${ }^{*} P<0.05$ 
a

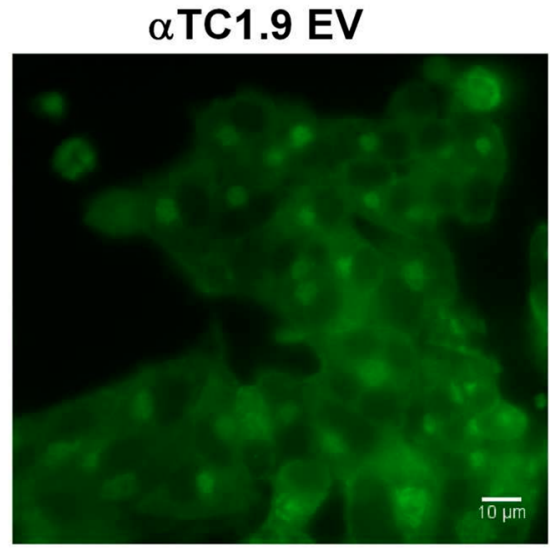

b

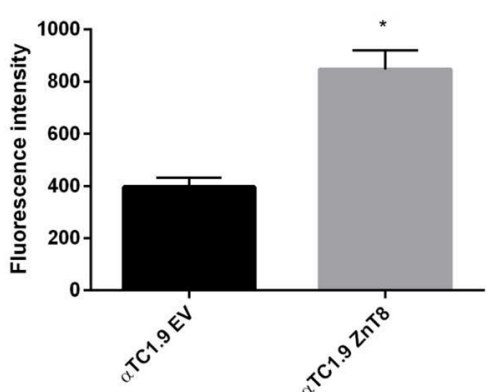

$\alpha$ TC1.9 ZnT8

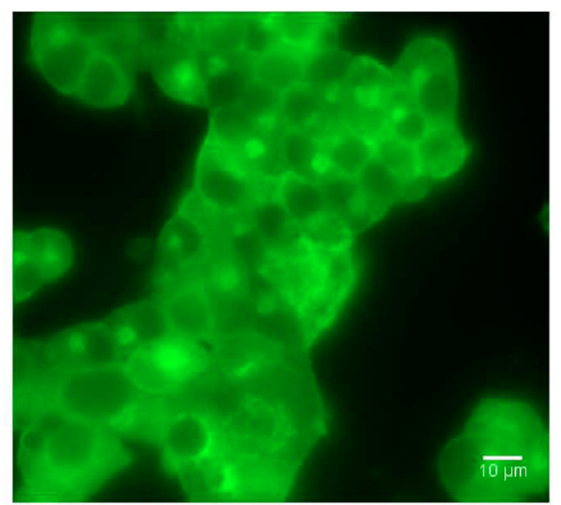

C

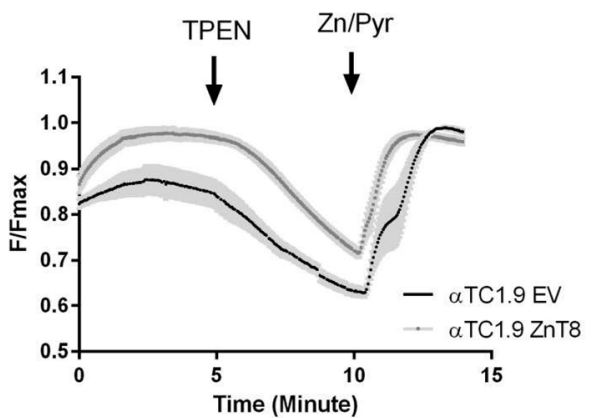

Fig. 5 Vesicular free $\mathrm{Zn}^{2+}$ assessment in aTC1.9 cells. aTC1.9 cells transfected with an expression vector encoding ZnT8 (aTC1.9 ZnT8) or empty vector (aTC1.9 EV) were incubated with ZinPyr4 (1 $\mu \mathrm{M})$ for $20 \mathrm{~min}$. before imaging. a Representative fields of view for aTC1.9 EV and aTC1.9 ZnT8 cells. b ZinPyr4 fluorescence intensity was determined on ten fields of view for two acquisitions, with constant light source power and exposure time. c Average traces. Acquisitions were performed under perifusion with imaging buffer and with addition as stated (TPEN $50 \mu \mathrm{M}$ - pyrithione $\left.(5 \mu \mathrm{M}) / \mathrm{Zn}^{2+}(100 \mu \mathrm{M})\right)$. Fluorescence intensity ratio was normalised as $\mathrm{F} / \mathrm{F}_{\max }$

using the granule-accumulated $\mathrm{Zn}^{2+}$ probe, Zinpyr4 [17] or in the cytosol with the recombinant-targeted Förster resonance energy-based probe, eCALWY4 [27]. Since individual $\alpha$ cells could not readily be identified in primary mouse islets from the transgenic animals, these experiments were performed using the clonal $\alpha$-cell line, $\alpha \mathrm{TC1}-9$ [29]. Whereas granular $\mathrm{Zn}^{2+}$ was significantly increased in the presence of exogenously-expressed $\mathrm{ZnT}$, as indicated by a substantial increase in the fluorescence of Zinpyr4 (Fig. 5), free $\mathrm{Zn}^{2+}$ concentrations tended to be lowered in the cytosol after ZnT8 overexpression (Fig. 6).

\section{Discussion}

In this report our aim was to overexpress ZnT8 in the pancreatic $\alpha$-cell in order to investigate the effect on glucagon secretion. The results, which demonstrate interesting parallels with respect to our findings in $\alpha \mathrm{ZnT} 8$ null animals [17], reveal that overexpression of ZnT8 in the $\alpha$-cell has no effect on glucose homeostasis or insulin sensitivity, as assessed by intraperitoneal tolerance tests. By contrast, increased $\alpha$-cell ZnT8 levels strongly affect responses to hypoglycaemia, as studied in hyperinsulinaemic clamps, as well as glucagon secretion in response to low glucose both in vivo and in vitro. The findings from the transgenic mouse with respect to glucagon release are thus reciprocal to those obtained in $\alpha Z n T 8$ null mice and further reinforce the view that ZnT8 has an important role in the $\alpha$-cell in regulating glucagon secretion.

Measured by qPCR in FACS-purified $\alpha$-cells from $\alpha Z n T 8 T g$ mice, human ZnT8 mRNA levels were approximately 0.6 times those of $\beta$-actin (Actb) mRNA (Fig. 1c). This value is similar to that measured for the murine ZnT8 homologue [17]. Assuming similar amplification efficiencies of the primers used for human and rodent $\mathrm{ZnT}$, and homogeneous expression across the entire $\alpha$-cell population, the above measurement implies roughly equivalent levels of mouse and human ZnT8 mRNA in transgenic $\alpha$-cells, i.e. a doubling of the endogenous level in wild type mice. We note, however, that though the more active (W325) human ZnT8 variant 
$\mathbf{a}$

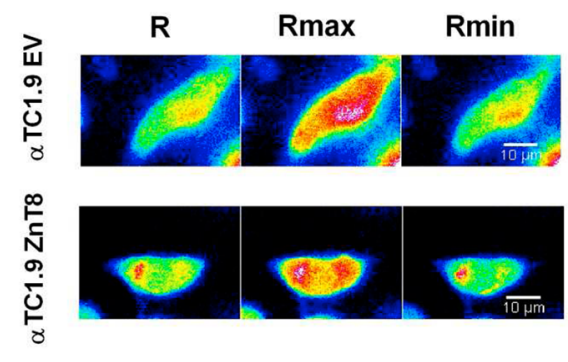

C

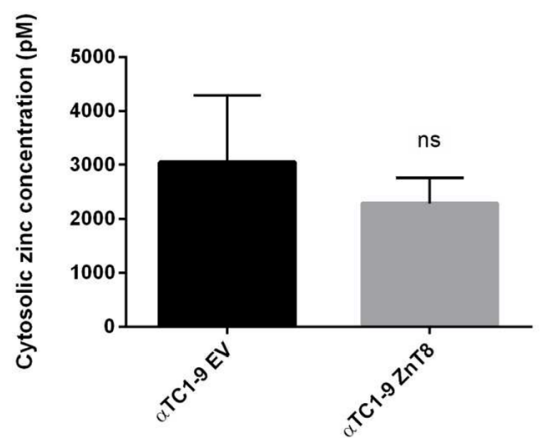

b

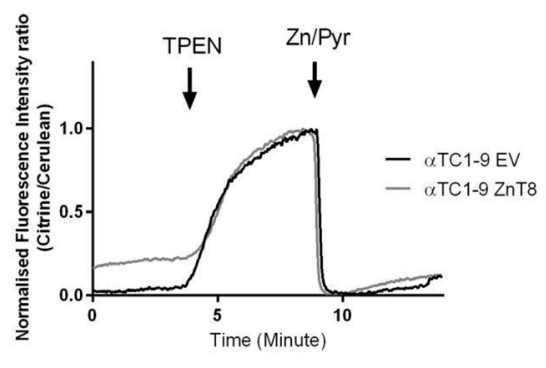

d

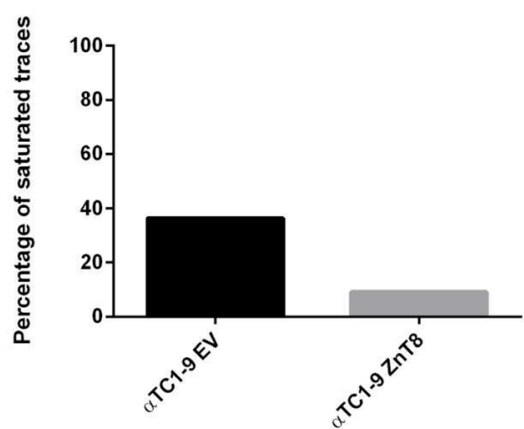

Fig. 6 Cytosolic free $\mathrm{Zn}^{2+}$ concentration measured using eCALWY-4 in aTC1.9 cells. aTC1.9 cells were co-transfected with an eCALWY-4 construct and with an expression vector for ZnT8 (aTC1.9 ZnT8) or empty vector (aTC1.9 EV). a Representative ratiometric images, obtained at steady state (R), under perfusion with the $\mathrm{Zn}^{2+}$ chelator $\mathrm{N}, \mathrm{N}, \mathrm{N}^{\prime}, \mathrm{N}^{\prime}$-tetrakis (2 pyridylmethyl) ethylenediamine (TPEN) $50 \mu \mathrm{M}\left(\mathrm{R}_{\max }\right)$ and under perfusion with pyrithione $(5 \mu \mathrm{M}) / \mathrm{Zn}^{2+}(100 \mu \mathrm{M})$ (Rmin). b Representative traces obtained. Fluorescence intensity ratio was normalised according to the formula: $\left(R-R_{\min }\right) /\left(R_{\max }-R_{\min }\right)$. c Using $R, R_{\min }$ and $R_{\max }$ values, cytosolic free $\mathrm{Zn}^{2+}$ concentrations were calculated for aTC1.9 EV cells (2 experiments - 7 cells) and aTC1.9 ZnT8 cells (2 experiments - 20 cells). $\mathbf{d}$ Percentage of cells presenting with a saturated sensor response (ie. cytosolic $\mathrm{Zn}^{2+}$ concentrations $>8 \mathrm{nM}$ )

was used in the present studies [7], the relative transporter activities of this versus the rodent (Q325) variant are not known, precluding a more accurate estimate of the extent of the increase in ZnT8 activity in $\alpha \mathrm{ZnT} 8 \mathrm{Tg}$ versus control $\alpha$-cells.

Likewise, efforts to quantify the degree of human ZnT8 expression in the $\alpha$-cell at the protein level were unsuccessful. These included immunostaining followed by islet dissociation, FACS analysis, and confocal imaging. Both approaches revealed limited affinity or selectively of the available antibodies towards human ZnT8 (Table 2). Thus, staining of islets did not reveal human ZnT8-positive populations in the face of high background staining (results not shown). Likewise, under FACS analysis, the entire population of islet cells from either control or $\alpha \mathrm{ZnT} 8 \mathrm{Tg}$ mice was found to be positive for human ZnT8 (results not shown). Similar findings were made over a range of primary and secondary antibody concentrations, and suggest at least partial reactivity of the anti-human antibody towards murine ZnT8. An anti-c-Myc antibody, aimed to detect the epitope tag present at the C-terminus of the ZnT8 transgene was also tested. Again, the staining was too weak across a range of primary antibody concentrations for meaningful quantitation (results not shown).
The results here complement those of a similar recent study from our laboratory [23]. In this earlier study, human ZnT8 was over-expressed in the adult $\beta$-cell using an insulin promoter-dependent Tet-On system. In the latter model, glucose-induced insulin secretion from $\beta Z n T 8 T g$ mice was impaired whereas $\mathrm{Zn}^{2+}$ release during stimulated exocytosis was elevated. A similar increase in granular $\mathrm{Zn}^{2+}$ content and secretion of these ions might reasonably be expected from $\alpha \mathrm{ZnT}$ Thg $\alpha$ cells especially since targeted deletion of $\mathrm{ZnT} 8$ led to a reduction of granular $\mathrm{Zn}^{2+}$ levels in both the $\alpha$ [17] and $\beta$ [23] cell. Likewise, changes in cytosolic free $\mathrm{Zn}^{2+}$ cells levels may occur after ZnT8 overexpression (as observed in $\beta$ cells after the deletion of the transporter) [32]. Measurements using targeted $\mathrm{Zn}^{2+}$ probes [33] revealed the expected changes in compartmentalised $\mathrm{Zn}^{2+}$ upon ZnT8 over-expression in the $\alpha$ cell line $\alpha$ TC1-9 (Figs. 5 and 6). Thus, it seems likely that ZnT8 over-expression also increased granular $\mathrm{Zn}^{2+}$ in the primary $\alpha$ cell in the transgenic mice. Future studies, in which the latter mouse line is crossed to a reporter strain allowing the expression and identification of a fluorescent marker in the $\alpha$ cell [17], will be required to confirm these observations. 
In addition to changes in cell function, we do not exclude the possibility that subtle changes (lowering) in $\alpha$ cell mass may also contribute to decreased glucagon release in $\alpha Z n T 8 \mathrm{Tg}$ mice, potentiating the impact on the acute release of the hormone observed after islet isolation (Fig. 4). Importantly, such changes may lead to alterations in the activity of signalling pathways the control cell survival [33]. Similarly, changes in the expression of genes involved in glucose sensing by $\alpha$-cells (e.g. glucokinase, Gck, or subunits of ATP-sensitive $\mathrm{K}^{+}$channels, i.e. Kcnj11or $A b c c 8$, etc.) [34, 35] may also contribute to altered glucagon release from $\alpha \mathrm{ZnT}$ \% Tg mouse islets. We note, however, that alterations in the latter were not observed after ZnT8 ablation [8] or overexpression [23] from $\beta$ cells. Changes in the expression of genes controlling glucagon synthesis or processing of the prohormone (e.g. Pcsk1 or Pcsk2) would appear unlikely given unaltered total glucagon levels in $\alpha \mathrm{ZnT} 8 \mathrm{Tg}$ islets (not shown).

Interestingly, over-expression of $\mathrm{ZnT} 8$ in the $\beta$ cell also substantially inhibited glucose-induced insulin release both in vivo and from isolated islets [23]. In both $\beta$ and $\alpha$ cells this might reflect slower dissolution of crystalline or other higher-order forms of the cargo hormones within secretory granules, impairing the formation and subsequent release of dimers or monomers through a diffusion-limiting pore [36]. $\beta Z$ ZnT 8 Tg mice nonetheless displayed enhanced glucose clearance compared to wild-type animals [23]. This change may be the consequence of increased $\mathrm{Zn}^{2+}$ release and an insulinomimetic action of these ions on target tissues [33], as well as impaired clearance of insulin by the liver [10]. By contrast, the impaired hypoglycemic response observed in $\alpha \mathrm{ZnT}$ TTg mice was largely in line with the observed decrease in plasma glucagon levels, arguing that any increase in $\mathrm{Zn}^{2+}$ co-release from the $\alpha$ cell is insufficient to compensate for the lowered levels of the latter hormone. In any case, we note that glucagon and $\mathrm{Zn}^{2+}$ are reported to exert opposing effects on glycolysis in the isolated liver cells, whilst exerting a similar, activating effect on glycogen breakdown [37].

\section{Conclusions}

In direct contrast to the activating effect of $\mathrm{ZnT}$ 8 deletion in $\alpha$ cells [17], overexpression of the transporter in these cells inhibits glucagon release under hypoglycaemic conditions. The present results thus reinforce the view that ZnT8 inhibition may be useful as a means to enhance glucagon release and hypoglycemic responses in the context of T1D. Conversely, activation of ZnT8 in the $\alpha$-cell, and inhibition of glucagon secretion, may be beneficial in $\mathrm{T} 2 \mathrm{D}$, complementing the effect of $\mathrm{ZnT} 8$ overexpression in $\beta$ cells to enhance insulin action [23]. Our findings also suggest that differences in the impact on T2D risk between rare [12] and more common [2] variants in the human SLC30A8/ZnT8 gene [13] might be explained in part by varying actions on glucagon release.

\begin{abstract}
Abbreviations
FACS, fluorescence-activated cell sorting; GIR, glucose infusion rate: rtTA, reverse tetracyclin transactivator; IPGT, IPITT, intraperitoneal glucose and insulin tolerance tests, respectively; T1D, T2D, type 1 and type 2 diabetes mellitus, respectively; TMEM, N,N,N',N'-tetrakis (2 pyridylmethyl) ethylenediamine
\end{abstract}

\section{Acknowledgements}

We are grateful to Dr Ahmed Mansouri (Max-Planck Institute, Goettingen, Germany) for providing Glu-rtTA transgenic mice and to Dr Lori Sussel (Barbara Davis Diabetes Center, University of Colorado, Denver) for aTC1-9 cells.

\section{Funding}

Supported by grants from Diabetes UK (Ph.D. studentship BDA 11/0004409 and Project BDA 11/0004210), the Wellcome Trust (Senior Investigator Award WT098424AIA), and the Medical Research Council (MRC) (Programme MR/J0003042/1) to G. A. R. This work was also supported by the Innovative Medicines Initiative Joint Undertaking under Grant Agreement 155005 (IMIDIA), resources of which are composed of financial contribution from the European Union's Seventh Framework Programme (FP7/2007-2013) and European Federation of Pharmaceutical Industries and Associations (EFPIA) companies.

\section{Authors' contributions}

GAR designed and coordinated the study, wrote the manuscript. AS performed mouse crosses, glucose tolerance and glucagon secretion studies. EP performed hypoglycemic clamps. PC performed zinc imaging, analysed data. SML performed hypoglycemic clamps. JG undertook glucagon measurements. JL supervised glucagon measurements and edited the manuscript. CM supervised clamps, analyzed data, edited the manuscript. All authors read and approved the final manuscript.

\section{Competing interests}

The authors declare that they have no competing interests.

\section{Ethics approval and consent to participate}

All in vivo procedures were approved by a local ethical committee (Animal Welfare and Ethics Review Board, AWERB) and conducted according to U.K. Home Office regulations (Animal Scientific Procedures Act of 1986, Home Office Project License number PPL 70/06608, holder Dr Isabelle Leclerc), in the Central Biological Services (CBS) unit at the Hammersmith Campus of Imperial College London.

\section{Author details}

'Section of Cell Biology and Functional Genomics, Division of Diabetes Endocrinology and Metabolism, Department of Medicine, Imperial College London, Imperial Centre for Translational and Experimental Medicine, Hammersmith Hospital, du Cane Road, London W12 ONN, UK. ${ }^{2}$ University Paris Diderot-Paris 7-Unit of Functional and Adaptive Biology (BFA) UMR 8251 CNRS, Paris, France. ${ }^{3}$ CNRS UMR 5248, Chimie et Biologie des

Membranes et Nano-objets, Université de Bordeaux, F-33615 Pessac, France.

Received: 4 January 2016 Accepted: 28 June 2016

Published online: 07 July 2016

References

1. Scully T. Diabetes in numbers. Nature. 2012;485:S2-3.

2. Sladek R, Rocheleau G, Rung J, Dina C, Shen L, Serre D, Boutin P, Vincent D, Belisle A, Hadjadj S, et al. A genome-wide association study identifies novel risk loci for type 2 diabetes. Nature. 2007:445:881-5.

3. Marullo L, El-Sayed Moustafa JS, Prokopenko I. Insights into the genetic susceptibility to type 2 diabetes from genome-wide association studies of glycaemic traits. Curr Diab Rep. 2014;14:551. doi:10.1007/s11892-014-0551-8. 
4. Rutter GA. Dorothy Hodgkin Lecture 2014. Understanding genes identified by genome-wide association studies for type 2 diabetes. Diabet Med. 2014; 31:1480-7. doi:10.1111/dme.12579.

5. da Silva Xavier G, Bellomo EA, McGinty JA, French PM, Rutter GA. Animal models of GWAS-identified type 2 diabetes genes. J Diabetes Res. 2013; 2013:906590. doi:10.1155/2013/906590. Epub 902013 Apr 906511.

6. Chimienti F, Devergnas S, Favier A, Seve M. Identification and cloning of a beta-cell-specific zinc transporter, ZnT-8, localized into insulin secretory granules. Diabetes. 2004;53:2330-7.

7. Nicolson TJ, Bellomo EA, Wijesekara N, Loder MK, Baldwin JM, Gyulkhandanyan AV, Koshkin V, Tarasov Al, Carzaniga R, Kronenberger K, et al. Insulin storage and glucose homeostasis in mice null for the granule zinc transporter ZnT8 and studies of the type 2 diabetes-associated variants. Diabetes. 2009;58:2070-83

8. Lemaire K, Ravier MA, Schraenen A, Creemers JW, Van de Plas R, Granvik M, Van Lommel L, Waelkens E, Chimienti F, Rutter GA, et al. Insulin crystallization depends on zinc transporter ZnT8 expression, but is not required for normal glucose homeostasis in mice. Proc Natl Acad Sci U S A. 2009:106:14872-7.

9. Pound LD, Sarkar SA, Benninger RK, Wang Y, Suwanichkul A, Shadoan MK, Printz RL, Oeser JK, Lee CE, Piston DW, et al. Deletion of the mouse SIc30a8 gene encoding zinc transporter-8 results in impaired insulin secretion. Biochem J. 2009;421:371-6.

10. Tamaki M, Fujitani Y, Hara A, Uchida T, Tamura Y, Takeno K, Kawaguchi M, Watanabe T, Ogihara T, Fukunaka A, et al. The diabetes-susceptible gene SLC30A8/ZnT8 regulates hepatic insulin clearance. J Clin Invest. 2013;123: 4513-24.

11. Kim I, Kang ES, Yim YS, Ko SJ, Jeong SH, Rim JH, Kim YS, Ahn CW, Cha BS, Lee HC, Kim CH. A low-risk ZnT-8 allele (W325) for post-transplantation diabetes mellitus is protective against cyclosporin A-induced impairment of insulin secretion. Pharmacogenomics J. 2011;11:191-8. doi:10.1038/tpj.2010. 22. Epub 2010 Mar 1030.

12. Flannick J, Thorleifsson G, Beer NL, Jacobs SB. Loss-of-function mutations in SLC30A8 protect against type 2 diabetes. Nat Genet. 2014;46:357-63.

13. Rutter GA, Chimienti F. SLC30A8 mutations in type 2 diabetes. Diabetologia. 2015;58:31-6.

14. Davidson HW, Wenzlau JM, O'Brien RM. Zinc transporter 8 (ZnT8) and beta cell function. Trends Endocrinol Metab. 2014;25:415-24.

15. Bramswig NC, Everett LJ, Schug J, Dorrell C, Liu C, Luo Y, Streeter PR, Naji A, Grompe M, Kaestner KH. Epigenomic plasticity enables human pancreatic alpha to beta cell reprogramming. J Clin Invest. 2013;123: 1275-84. doi:10.1172/JCl66514. Epub 62013 Feb 66522.

16. Kristiansen LH, Rungby J, Sondergaard LG, Stoltenberg M, Danscher G. Autometallography allows ultrastructural monitoring of zinc in the endocrine pancreas. Histochem Cell Biol. 2001;115:125-9.

17. Solomou A, Meur G, Bellomo E, Hodson DJ, Tomas A, Li SM, Philippe E, Herrera PL, Magnan C, Rutter GA. The zinc transporter Slc30a8/ZnT8 is required in a subpopulation of pancreatic alpha-cells for hypoglycemia-induced glucagon secretion. J Biol Chem. 2015;290: 21432-42. doi:10.1074/jbc.M115.645291. Epub 642015 Jul 645215

18. Tamborlane WV, Amiel SA. Hypoglycemia in the treated diabetic patient A risk of intensive insulin therapy. Endocrinol Metab Clin North Am. 1992;21: 313-27.

19. Gossen $M$, Bujard $H$. Tight control of gene expression in mammalian cells by tetracycline-responsive promoters. Proc Natl Acad Sci U S A. 1992;89: 5547-51.

20. Gossen M, Freundlieb S, Bender G, Muller G, Hillen W, Bujard H. Transcriptional activation by tetracyclines in mammalian cells. Science. 1995;268:1766-9.

21. Milo-Landesman D, Surana M, Berkovich I, Compagni A, Christofori G, Fleischer N, Efrat S. Correction of hyperglycemia in diabetic mice transplanted with reversibly immortalized pancreatic beta cells controlled by the tet-on regulatory system. Cell Transplant. 2001;10:645-50.

22. Al-Hasani K, Pfeifer A, Courtney M, Ben-Othman N, Gjernes E, Vieira A Druelle N, Avolio F, Ravassard P, Leuckx G, et al. Adult duct-lining cells can reprogram into beta-like cells able to counter repeated cycles of toxin-induced diabetes. Dev Cell. 2013;26:86-100.

23. Mitchell RK, Hu M, Chabosseau PL, Cane MC, Meur G, Bellomo EA, Carzaniga R, Collinson LM, Li WH, Hodson DJ, Rutter GA. Molecular genetic regulation of $\mathrm{Slc30a8/ZnT8}$ reveals a positive association with glucose tolerance. Mol Endocrinol. 2015. doi:10.1210/me.2015-1227
24. Ravier MA, Rutter GA. Isolation and culture of mouse pancreatic islets for ex vivo imaging studies with trappable or recombinant fluorescent probes. Methods Mol Biol. 2010;633:171-84. doi:10.1007/1978-1001-59745-5901959745 59712.

25. Bellomo EA, Meur G, Rutter GA. Glucose regulates free cytosolic Zn(2)(+) concentration, Slc39 (ZiP), and metallothionein gene expression in primary pancreatic islet beta-cells. J Biol Chem. 2011;286:25778-89. doi:10.1074/jbc. M111.246082. Epub 242011 May 246025.

26. Chabosseau P, Tuncay E, Meur G, Bellomo EA, Hessels A, Hughes S, Johnson PR, Bugliani M, Marchetti P, Turan B, et al. Mitochondrial and ER-targeted eCALWY probes reveal high levels of free Zn2+. ACS Chem Biol. 2014;9: 2111-20. doi:10.1021/cb5004064. Epub 5002014 Jul 5004017.

27. Vinkenborg JL, Nicolson TJ, Bellomo EA, Koay MS, Rutter GA, Merkx M. Genetically encoded FRET sensors to monitor intracellular Zn2+ homeostasis. Nat Methods. 2009:6:737-40. doi:10.1038/nmeth.1368. Epub 2009 Aug 1030.

28. Elayat AA, el-Naggar MM, Tahir M. An immunocytochemical and morphometric study of the rat pancreatic islets. J Anat. 1995;186:629-37.

29. Ravier MA, Rutter GA. Glucose or insulin, but not zinc ions, inhibit glucagon secretion from mouse pancreatic alpha-cells. Diabetes. 2005;54:1789-97.

30. Evans ML, Sherwin RS. Brain glucose metabolism and hypoglycaemia. Diabetes Nutr Metab. 2002;15:294-6. discussion 296.

31. Taborsky Jr GJ, Ahren B, Mundinger TO, Mei Q, Havel PJ. Autonomic mechanism and defects in the glucagon response to insulin-induced hypoglycaemia. Diabetes Nutr Metab. 2002;15:318-22. discussion 322-313.

32. Gerber PA, Bellomo EA, Hodson DJ, Meur G, Solomou A, Mitchell RK, Hollinshead M, Chimienti F, Bosco D, Hughes SJ, et al. Hypoxia lowers SLC30A8/ZnT8 expression and free cytosolic Zn2+ in pancreatic beta cells. Diabetologia. 2014;57:1635-44. doi:10.1007/s00125-014-3266-0. Epub 02014 May 00128.

33. Rutter GA, Chabosseau P, Bellomo EA, Maret W, Mitchell RK, Hodson DJ, Solomou A, Hu M. Intracellular zinc in insulin secretion and action: a determinant of diabetes risk? Proc Nutr Soc. 2015:14:1-12.

34. Schuit FC, Huypens P, Heimberg H, Pipeleers DG. Glucose sensing in pancreatic beta-cells: a model for the study of other glucose-regulated cells in gut, pancreas, and hypothalamus. Diabetes. 2001;50:1-11.

35. Walker JN, Ramracheya R, Zhang Q, Johnson PR, Braun M, Rorsman P. Regulation of glucagon secretion by glucose: paracrine, intrinsic or both? Diabetes Obes Metab. 2011;13:95-105. doi:10.1111/j.1463-1326.2011.01450.x.

36. Tsuboi T, Rutter GA. Multiple forms of "kiss-and-run" exocytosis revealed by evanescent wave microscopy. Curr Biol. 2003;13:563-7.

37. Brand IA, Kleineke J. Intracellular zinc movement and its effect on the carbohydrate metabolism of isolated rat hepatocytes. J Biol Chem. 1996; 271:1941-9.

\section{Submit your next manuscript to BioMed Central and we will help you at every step:}

- We accept pre-submission inquiries

- Our selector tool helps you to find the most relevant journal

- We provide round the clock customer support

- Convenient online submission

- Thorough peer review

- Inclusion in PubMed and all major indexing services

- Maximum visibility for your research

Submit your manuscript at www.biomedcentral.com/submit 